\title{
Correction to: Visualising the Link Between Carpal Bones and Their Etymologies
}

Kaitlin Nasrala, Matthieu Poyade, and Eilidh Ferguson

\section{Correction to: \\ Chapter 6 in: P. M. Rea (ed.), Biomedical Visualisation, Advances in Experimental Medicine and Biology 1334, https://doi.org/10.1007/978-3-030-76951-2_6}

The original version of Chapter 6 was inadvertently published with only the second affiliation of the author Kaitlin Nasrala, but her first affiliation was missing. This has now been corrected.

The updated online version of this chapter can be found https://doi.org/10.1007/978-3-030-76951-2_6 